\title{
Multiphase Modeling of the Fluidynamics of Bottom Argon Bubbling during Ladle Operations
}

\author{
Carlos A. LLANOS, ${ }^{1)}$ Saul GARCIA-HERNANDEZ ${ }^{21}{ }^{2}$ J. Anǵel RAMOS-BANDERAS, ${ }^{3)}$ Jose de J. BARRETO ${ }^{3)}$ \\ and Gildardo SOLORIO-DIAZ ${ }^{4}$
}

1) Graduate Student, Metallurgy Graduate Center, Instituto Tecnológico de Morelia, Av. Tecnológico No. 1500 C.P. 58120 , Morelia, Michoacán, México. $\quad$ 2) Graduate Student, Department of Metallurgy and Materials Engineering, Instituto Politécnico Nacional-ESIQIE, Mexico D. F., C. P. 07738, México. E-mail: iq_sagahz@hotmail.com 3) Instituto Tecnológico de Morelia, Metallurgy Graduate Center, Av. Tecnológico No. 1500 C.P. 58120, Morelia, Michoacan, México. E-mail: jramos@itmorelia.edu.mx; jbarreto@itmorelia.edu.mx 4 4) Universidad Michoacana de San Nicolás de Hidalgo, Posgrado en Ingeniería Mecánica, Av. F.J. Mújica S/N CP. 58040, Morelia Michoacan, México. E-mail: gil_6000@hotmail.com

(Received on September 24, 2009; accepted on December 1, 2009)

\begin{abstract}
The objective of the present study is the optimization of the ladle stirring operation through a multiphase mathematical model and an analogue physical model. Four cases were considered using one and two argon injection inlets with different configuration, where the multiphase steel/slag/argon system was simulated numerically in Three-Dimensional Unsteady State conditions and a water/oil/air system for the physical model was considered. The Volume of Fluid (VOF) model was employed to simulate numerically the interaction among the phases considering the surface tensions. The simulation results were evaluated by a fluidynamics analysis of the systems and by a numerical prediction of three important operation parameters: mixing time, lining refractory wear and slag opening. The implementation of two argon inlets did not reduce the mixing time; however, the slag layer opening was decreased in a $30 \%$, and the refractory wear in terms of the skin friction coefficient value was also decreased in a $63 \%$. These results confirm that it is imperative to consider, for numerical simulation, the three phases present during ladle operations.
\end{abstract}

KEY WORDS: ladle metallurgy; multiphase systems; physical modeling; mathematical simulation.

\section{Introduction}

For the context of improving the steel quality products, secondary metallurgy plays an important role in modern steelmaking processes. Ladle metallurgy is mainly employed to carry out refining operations. It is well known, that submerged gas injections into liquid steel contained in the ladle is an effective method to enhance chemical reaction rates, homogenize chemical compositions, remove non-metallic inclusions and eliminate temperature stratification. Many studies related to gas injection into liquid steel have been published in the past ${ }^{1-14)}$; for instance, the in depth review of the physical and mathematical modeling presented by Mazumdar and Guthrie, ${ }^{15)}$ where they mention that none of the models included the slag phase. In a further study Jonsson et al. ${ }^{16)}$ recommended to consider the incorporation of the slag layer for a more accurate modeling of steel velocities at the slag/steel interface in a gas stirred ladle. Mietz and Oeters ${ }^{17}$ ) studied the effect of the gas flow rate and the porous plug location on mixing time in a water model, where an improvement of mixing time and a reduction of death zones were accomplished with a single offcentered porous plug. Krishnapisharody and Irons ${ }^{18)}$ derived models using dimensionless variables to predict the spout and slag eye formation, they estimated the operational limits of gas flow rates in a single porous plug prac- tice, in order to achieve optimal performance. Maruoka et $a l .{ }^{19)}$ correlated the mixing time and the plume eye area to the volumetric mass transfer coefficient in a water model experiment, they claim that the coefficient of surface reaction increases with the gas flow rate and that is strongly dependent on plume eye area, but it is not related directly to mixing time. Yang et al. ${ }^{20)}$ used a multiphase model to predict the slag layer behavior, incorporating Electro Magnetic Stirring (EMS) to the system, they found that with this system can control the shape of the gas plume, and the mixing time was reduce by the circulating flow of the melt created by EMS, but slag opening can be spontaneously increased. Recently Li et al. ${ }^{21)}$ studied the behavior of the slag/steel interface using different gas flow rates. They calculated the deformation and the slag layer opening, arguing that the slag emulsification is due to higher downward flow velocities. To date is extremely difficult to simulate the complex phenomena involved in gas stirring systems, for this many different modeling considerations have been made. Due to the few studies that includes the slag layer in the numerical modeling, ${ }^{20,21)}$ the present study focus on the consideration of two further important operational parameters, such as the slag layer opening and the lining refractory wear, using a multiphase mathematical model and an analogue water model, where the steel/slag/argon system was simulated numerically in Three-Dimensional Unsteady State condi- 


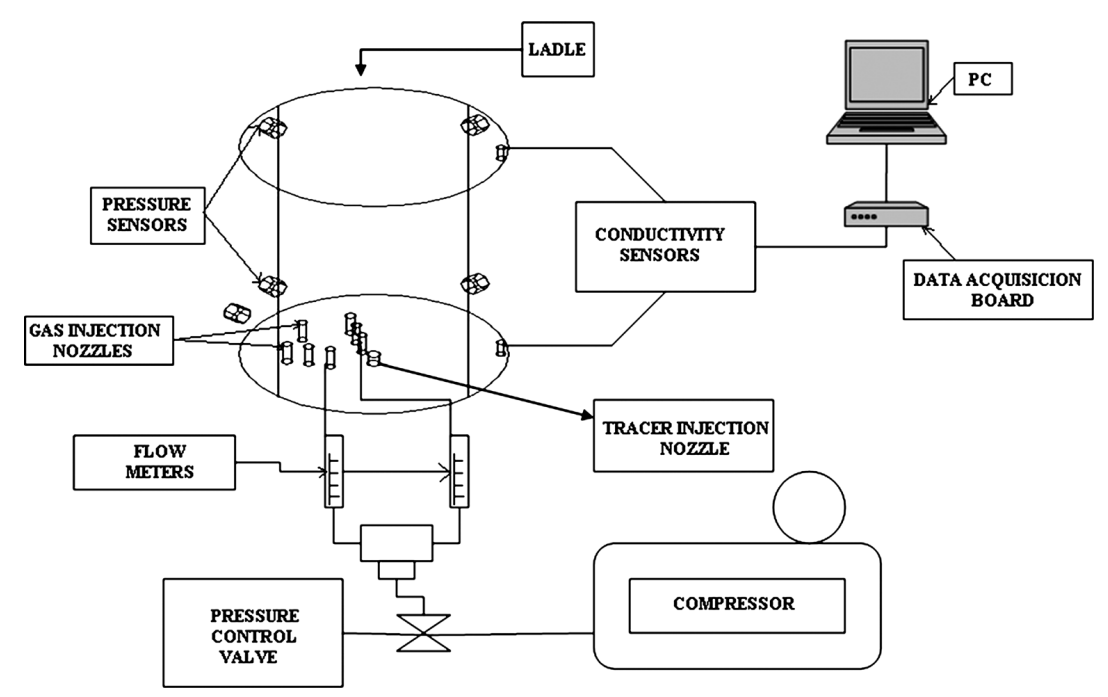

Fig. 1. Schematic view of the experimental setup.

tions and the water/oil/air system for the analogue model was considered. The Volume of Fluid (VOF) model was employed to simulate numerically the interaction among the phases considering the surface tensions.

\section{Physical Model}

Experimental water modeling was carried out in a $1 / 6$ scaled model from prototype which was built of $9 \mathrm{~mm}$ transparent Perspex. The model was scaled using the modified Froude number, which considers the inertial and buoyancy forces acting during ladle stirring operation. The real system, steel-argon-slag, was replaced by a water-air-oil system, taking advantages of flow dynamics similitude as well as availability. In order to model slag layer behavior, vegetal oil was selected which has successfully been employed in other studies. ${ }^{14,22-24)}$ Red dye tracer was used to analyze the fluidynamics of the model; the dye was injected at center of the ladle bottom. In order to measure mixing time a $3.35 \mathrm{M}$ solution of $\mathrm{KCl}$ was injected at the same point, and the conductivity of the water was measured to 95\% mixing criteria by the sensors shown in Fig. 1; where the experimental setup employed for the physical experimentation is schematized. The ladle model was filled up to $0.532 \mathrm{~m}$ height, representing 136 steel tons in prototype; the slag layer width in model was $0.0083 \mathrm{~m}$, representing 0.05 $\mathrm{m}$ in the prototype. Due to scarce information about porous plug properties for modeling air injection, the inlets were considered as nozzles for all of the cases studied.

\section{Mathematical Model}

\subsection{Fundamental Equations}

The liquid steel, liquid slag, argon flow and atmospheric air were considered in the mathematical model. Their behavior are governed by the Navier-Stokes equations, together with well known $k-\varepsilon$ turbulence model ${ }^{25}$ and the Volume of Fluid model. ${ }^{13)}$ The equations in the Cartesian coordinate system are written as follow:

- The Continuity Equation

$$
\nabla \cdot(\rho \vec{v})=0
$$

- The Momentum Equation

A single momentum equation is solved throughout the domain and the resulting velocity field is shared among the phases, this equation is dependent on the volume fraction of all phases through the properties $\rho$ and $\mu$,

$$
\frac{\partial}{\partial t}(\rho \vec{v})+\nabla \cdot(\rho \vec{v} \vec{v})=-\nabla p+\nabla \cdot\left[\mu\left(\nabla \vec{v}+\nabla \vec{v}^{T}\right)\right]-\rho \vec{g}+F
$$

- The Two Equations $k-\varepsilon$ Turbulence Model

$$
\begin{aligned}
& \rho \frac{\partial k}{\partial t}+\rho \frac{\partial k u_{i}}{\partial x_{i}}=\frac{\partial}{\partial x_{j}}\left[\left(\mu+\frac{\mu_{t}}{\sigma_{k}}\right) \frac{\partial k}{\partial x_{j}}\right]+G_{k}-\rho \varepsilon \\
& \rho \frac{\partial \varepsilon}{\partial t}+\rho \frac{\partial \varepsilon u_{i}}{\partial x_{i}} \\
& =\frac{\partial}{\partial x_{j}}\left[\left(\mu+\frac{\mu_{t}}{\sigma_{\varepsilon}}\right) \frac{\partial \varepsilon}{\partial x_{j}}\right]+C_{1 \varepsilon} \frac{\varepsilon}{k} G_{k}-C_{2 \varepsilon} \rho \frac{\varepsilon^{2}}{k}
\end{aligned}
$$

- Multiphase Model

The VOF formulation relies on the fact that two or more fluids or phases are not interpenetrating. For each additional phase added to the model, a new variable is introduced (the volume fraction in the computational cell). A continuity equation has to be solved for the volume fraction of one or more of the phases.

$$
\frac{\partial \alpha_{q}}{\partial t}+\vec{v} \cdot \nabla \alpha_{q}=\frac{S \alpha_{q}}{\rho_{q}}
$$

\subsection{Modeling Conditions}

Figure 2 shows the prototype geometry dimensions that were used to develop the three-dimensional model in a 


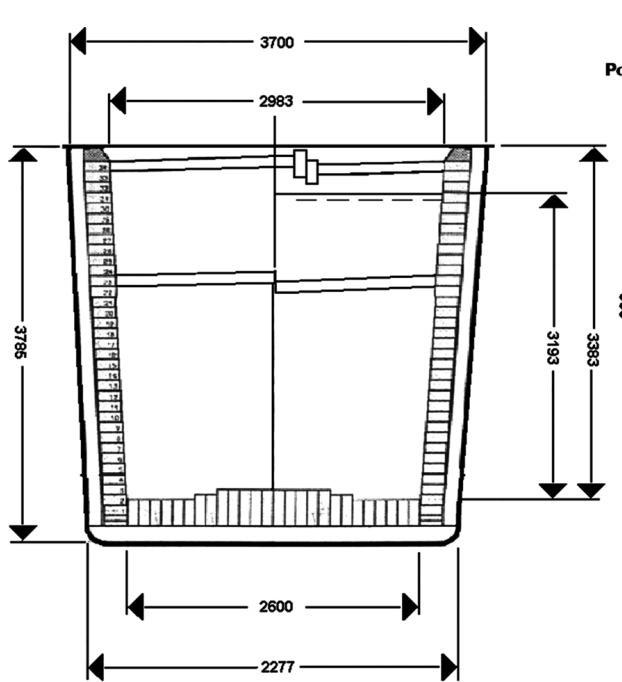

a)

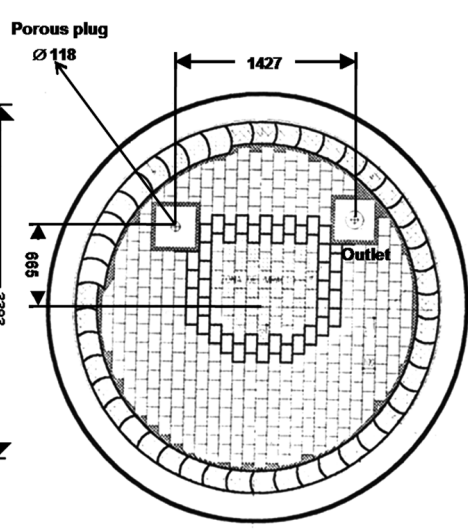

b)

Fig. 2. Prototype geometrical dimensions (mm). a) Lateral view and b) upper view.

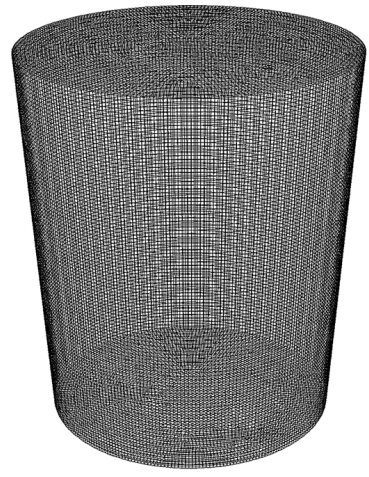

a)

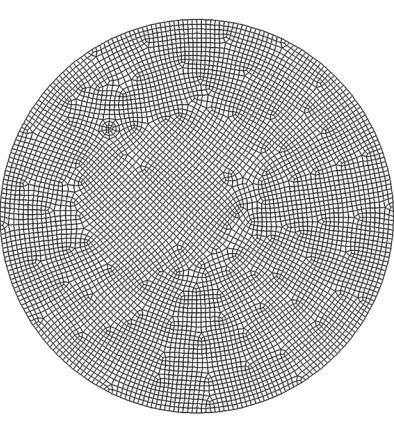

b)
Fig. 3. Computational mesh. a) Isometric view and b) upper view.

Cartesians Co-ordinates system. The following assumptions for the liquid steel, slag and argon gas bubbles are made in this model.

(1) Unsteady state conditions were used for all cases for the all phases.

(2) The liquid steel and slag behave like an incompressible Newtonian fluid and with constant viscosity flow process.

(3) Non-slipping conditions were applied at all solid surfaces and wall functions were used at nodes close to any wall.

(4) Gravity force was taken to act over $y$-axis.

(5) The interfaces were calculated using the VOF model, where interfacial tensions among fluids were considered.

(6) The shape and the possibility of coalescence and break up among bubbles were determined by the VOF model.

The computational structured grid, conformed of 800000 cells, for the full capacity of the ladle is shown in the Fig. 3. The studied cases and its conditions are defined in Table 1, where the constant argon flow was divided by half for the cases with two argon inlets. The physical properties used for all phases are shown in the Table 2. The mathematical model was solved using the commercial Software FLUENT ${ }^{\circledR}$.
Table 1. Description of the cases studied.

\begin{tabular}{|c|c|c|}
\hline Case & Argon inlets location & $\begin{array}{l}\text { Argon } \\
\text { flow }\end{array}$ \\
\hline 1 & One inlet located at $3 / 4 \mathrm{r}$ & \\
\hline 2 & Two inlets located at $2 / 3 \mathrm{r}$, with $60^{\circ}$ separation & 1.5 \\
\hline 3 & Two inlets located at $3 / 4 \mathrm{r}$ and $2 / 3 \mathrm{r}$ respectively, with $60^{\circ}$ separation & $\mathrm{Nm}^{3} / \mathrm{min}$ \\
\hline 4 & $\begin{array}{l}\text { Two inlets located at } 3 / 4 \mathrm{r} \text { and } 2 / 3 \mathrm{r} \text { respectively, with } 60^{\circ} \text { separation. } \\
\text { The first one with } 5 \text { degrees inclination to the center. }\end{array}$ & \\
\hline
\end{tabular}

Table 2. Fluid properties.

\begin{tabular}{|c|c|}
\hline Property & Value \\
\hline Steel density & $7020 \mathrm{~kg} / \mathrm{m}^{3}$ \\
\hline Steel viscosity & $0.006 \mathrm{~kg} / \mathrm{m}-\mathrm{s}$ \\
\hline Slag density & $3500 \mathrm{~kg} / \mathrm{m}^{3}$ \\
\hline Slag viscosity & $0.2664 \mathrm{~kg} / \mathrm{m}-\mathrm{s}$ \\
\hline Argon density & $1.6228 \mathrm{~kg} / \mathrm{m}^{3}$ \\
\hline Argon viscosity & $2.125 \times 10^{-5} \mathrm{~kg} / \mathrm{m}-\mathrm{s}$ \\
\hline Surface tension slag/steel & $0.12 \mathrm{~N} / \mathrm{m}$ \\
\hline Surface tension steel/argon & $1.192 \mathrm{~N} / \mathrm{m}$ \\
\hline Water density & $998.2 \mathrm{~kg} / \mathrm{m}^{3}$ \\
\hline Water viscosity & $0.001 \mathrm{~kg} / \mathrm{m}-\mathrm{s}$ \\
\hline Air density & $1.225 \mathrm{~kg} / \mathrm{m}^{3}$ \\
\hline
\end{tabular}



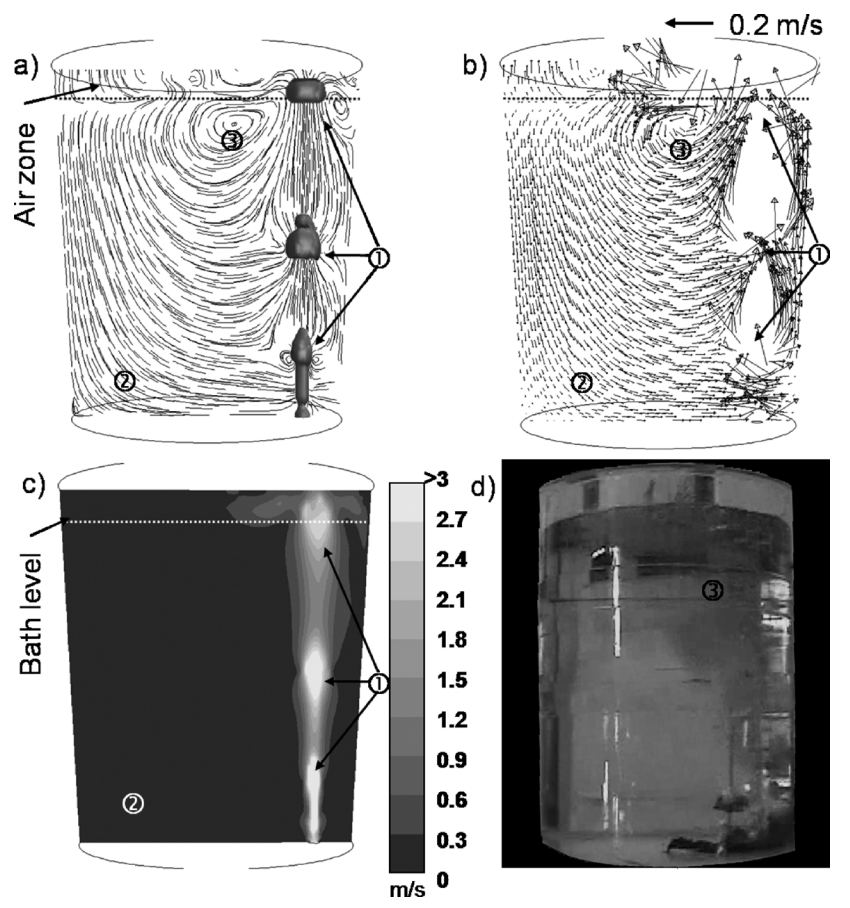

Fig. 4. Numerical and physical parameters for case 1 taken on a vertical plane along the gas inlet and the ladle center, a) path lines, b) velocity vectors, c) velocity contours and d) physical tracer injection photography.

\section{Results and Discussion}

\subsection{Fluidynamic Analysis}

Figure 4 shows the physical and numerical results for case 1. Figures 4(a)-4(c) show the path lines, velocity vectors and contours, respectively. All these figures were taken on a vertical plane along the center of the purging gas nozzle and the ladle midpoint. Figure 4(d) shows the red dye tracer injection into the physical model. Figures 4(a)-4(c) show the rising argon bubbles driven by buoyancy force effect, where the point (1) indicates the zone where the velocity values exceeded $3 \mathrm{~m} / \mathrm{s}$. These bubbles are responsible for momentum transfer to their surrounding steel generating its ascending movement to the free surface. Argon bubbles follow its rising trajectory throughout slag layer whilst liquid steel flows below the slag phase turning back away from the gas plume towards the bottom, drawing a recirculation closed loop. As steel transfers its momentum to the whole bulk by shear stress it loses velocity as indicated by point (2) in Figs. 4(a)-4(c). This flow cycle induce a main re-circulating eye identified by point (3) located at the upper part of the ladle and lightly deviated from the bubbles jet. Figure 4(d) shows that the red dye tracer follows the same trajectory described for the numerical results, where point (3) confirms the above mentioned recirculation eye.

Figures 5(a)-5(d) show the numerical results for cases 2, 3 and 4 ; at the same plane location taken for case 1 . The argon injection point for case 1 was taken as a reference to position the second injection point. Figures 5(a) and 5(b) show the flow patterns for case 2 , the first one correspond to path lines and the second to the velocity contours. It was found that even for the two argon injections points, the steel flow follows similar trajectories, shown in case 1. However, the contours show lesser velocity intensities at point (1) than
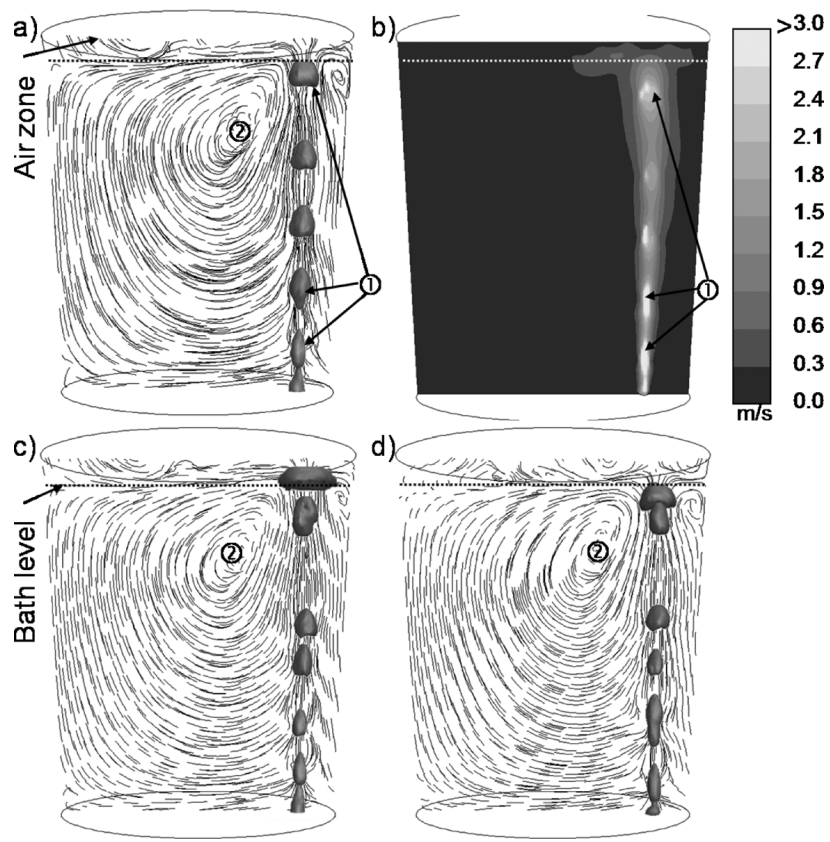

Fig. 5. Numerical parameters for case 2 to 4 taken on a vertical plane along the first gas inlet and the ladle center; a) case 2 path lines, b) case 2 velocity contour, c) case 3 path lines and d) case 4 path lines.

in the case 1 , which is a result of dividing the volumetric argon flow into the two inlets. Other important difference is the re-circulating flow eye location; while for case 1 the eye is closed to the interface steel/slag, for the case 2 the re-circulation is bigger with more steel volume and moved its position slightly down from the bath level, as shown at point (2). Figures 5(c) and 5(d) show the fluidynamics for cases 3 and 4, respectively; these two cases presented the same flow pattern that case 2 , consequently the same differences with case 1 . Hence, the flow analysis is mainly focused on first two cases.

Figure 6 shows the velocity vectors on three transversal planes located at $0.2 \mathrm{~m}, 1.5 \mathrm{~m}$ and $3 \mathrm{~m}$ from ladle bottom, for cases 1 and 2. Figures 6(a) and 6(d) show the upper flow field for both cases at $3 \mathrm{~m}$ height. Case 1 shows higher velocity values near the wall and the lowest one in the center of the ladle; and in the case 2 the flow is more uniform, showing similar flow velocity throughout the ladle center as well as near the wall. This phenomenon is directly related to the amount of steel volume that acquire momentum from the argon bubbles and moves towards the center of the bath, being smaller for the case 1 than for the other analyzed cases. If the amount of steel that is moving to the center is small, the re-circulation is formed close to the free surface (case 1), but if the amount of steel increases, the re-circulation moves towards the inside of the steel bulk (cases 2-4). Figures 6(b)-6(f) show the remained planes, where is clear that not only exist a downstream flow towards the ladle bottom, but also the rising bubbles exert a transversal flow movement towards the bubbles zone. For case 2 it can be seen a slightly increase on the velocity magnitude in both transversal planes, this is a consequence of a greater steel volume in movement. 

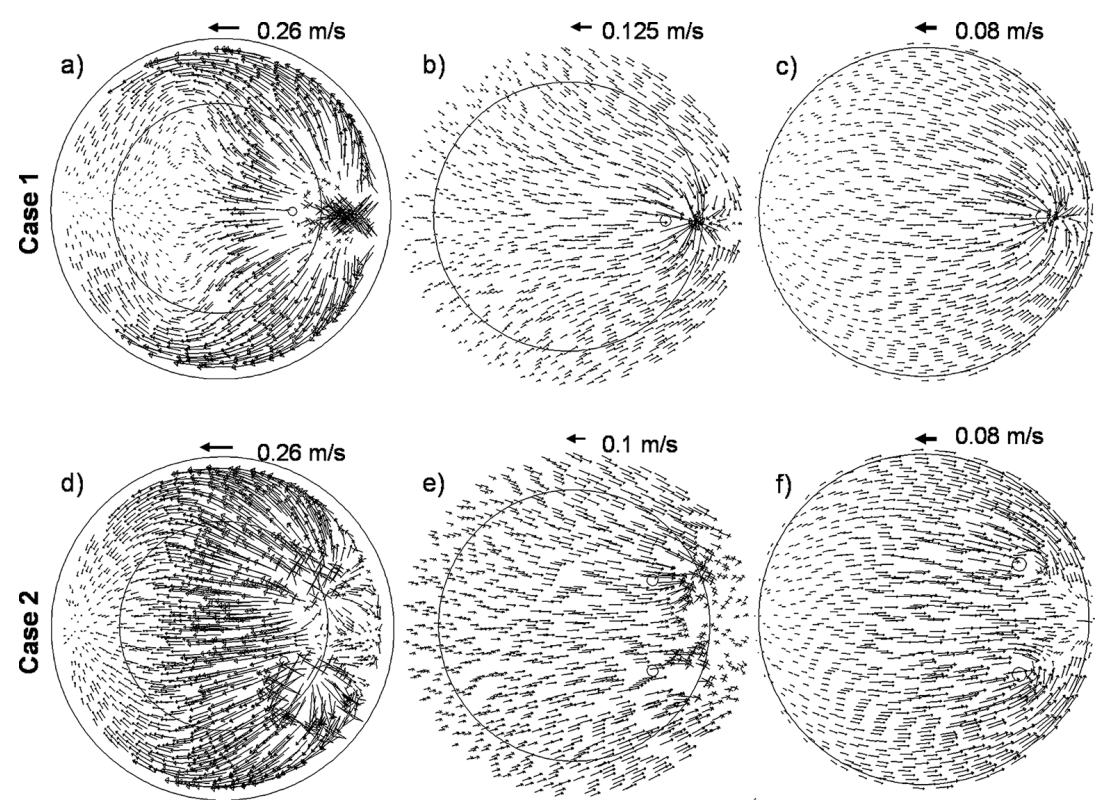

Fig. 6. Velocity vectors on three transversal planes located at $3 \mathrm{~m} \mathrm{[a)} \mathrm{and} \mathrm{d)],} 1.5 \mathrm{~m}[\mathrm{~b}$ ) and e)] and $0.2 \mathrm{~m}$ [c) and f)] for the two first cases.

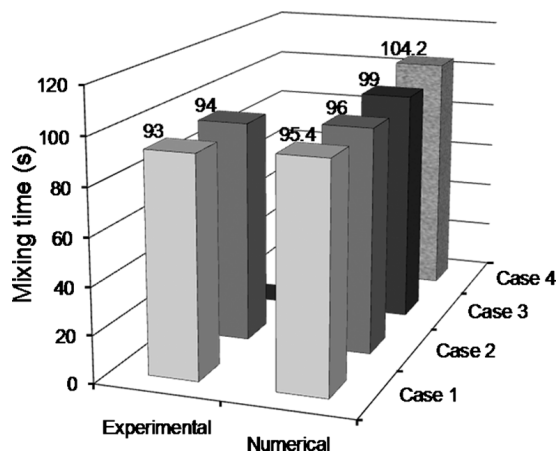

Fig. 7. Physical and numerical values for the mixing time parameter.

\subsection{Mixing Time Parameter}

Up to now, the fluidynamic patterns have been described during the stirring operation with one and two argon injection nozzles, finding out great similitude for the cases studied, which makes impossible to suggest a proposal to improve the mixing operation of the ladle. For this reason, it was necessary to move further to determine physically and numerically the mixing time. Due to Software facilities it was possible to calculate the mixing time for all cases, and in order to validate the numerical results this parameter was measured in the physical model only for the first two cases, the values obtained are graphically shown in Fig. 7. A 98\% agreement was obtained in this validation; even though, comparing the mixing time value for the 4 numerical cases, the difference between the highest and the lowest time is just about $8.8 \mathrm{~s}$, which means that mixing time parameter is neither a determinant factor to decide the operation conditions. Therefore, it was necessary to select another variable to be in a better position to take the best decision, for this an important industrial parameter was selected, the ladle lining wear.

\subsection{Wall Skin Friction Coefficient}

It is clearly impossible to measure ladle lining wear by
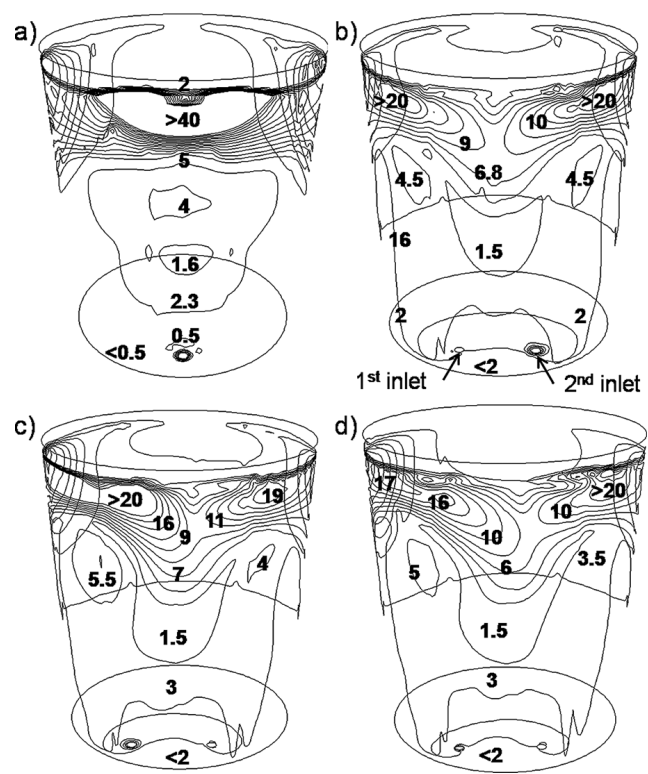

Fig. 8. Wall skin friction coefficient contours, a) case 1, b) case 2, c) case 3 and d) case 4 .

any of the models developed in this study; however, it is possible to associate the areas of lining wear to the wall skin friction coefficient, which is directly proportional to shear stress between steel flow and ladle wall. The wall skin friction coefficient was computed for all cases and the results are shown in Fig. 8. Figure 8(a) shows the corresponding results for case 1 , where the coefficient is low from the bottom to the middle of the ladle wall, increasing from this height to the free surface, close to this surface great increase is shown; this is due to the break of the bubbles at the interface steel/slag, generating a strong stirring close to the wall near the argon plume, being the main reason of the higher skin friction coefficient values reported. The skin friction coefficient decreases considerably when the volumetric argon flow is divided into the two inlets, as shown in Figs. 8(b)-8(d). For case 2, Fig. 8(b) shows that the coefficient profile has symmetry; however, this does not occur in 


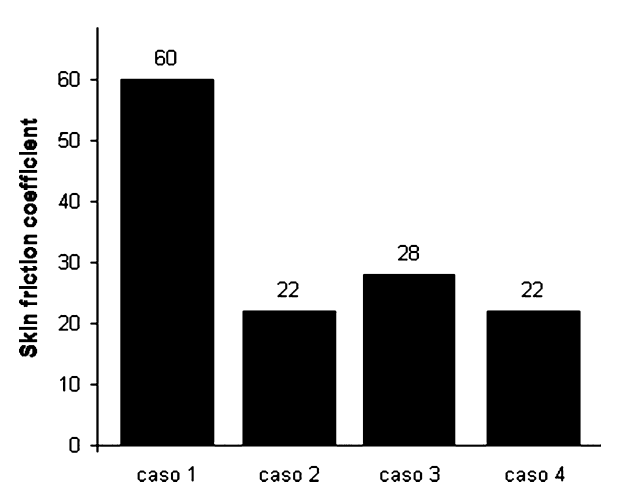

Fig. 9. Maximum values of the skin friction coefficient.

the two other cases, as shown in Figs. 8(c) and 8(d). This can be explained considering that in these two late cases, the argon inlets are located at different lengths from the ladle center; this provokes that bubbles break at two different asymmetric points at the interface steel/slag. It is important to stress that for case 4 the argon input has a 5 degrees inclination towards the ladle center, which reduces the wall skin friction coefficient at its corresponding bubble braking point. Figure 9 shows the maximum values for the skin friction coefficient, where is clear that any of the two argon inlets cases are better than the case 1. Even with these results is not possible to establish the optimum operation conditions; for this, it was necessary to consider a further parameter, the slag opening area.

\subsection{Slag Opening Area}

In the past this important parameter had not been considered in mathematical modeling due to the hardware and software limitations. ${ }^{1-19)}$ In order to consider the slag phase the multiphase model described above was applied to simulate the complete ladle system, this includes the argon injection, slag aperture and steel stirring. Likewise to the mixing time the slag opening was physical and numerical simulated, the results are shown in Fig. 10. In this figure, it can be observed that the slag opening is very similar in the models; however, the opening area is slightly smaller for the physical model. This can be explained indicating that in this model, where it was used a Water/Oil/Air system, the surface tensions are unknown and clearly they play a very important role in the oil opening area. In order to validate the numerical model, is necessary to observe the opening patterns of the slag and the oil: For case 1, in Fig. 6(a) it can be seen that the steel moves at a higher velocity close to the ladle walls than it does for the center; under this pattern is expected that the slag shows a higher opening closer to the walls and not in the center, this is revealed in the both models in Figs. 10(a) and 10(c) (point (1)). For case 2, in Fig. 6(d) it can be seen that the steel moves at a more uniform velocity; for this, it can be expected that the slag opening be equally uniform as shown in Figs. 10(b) and 10(d) (point (2). Consequently the numerical model can be considered validated; for this, the slag opening patterns and the quantification of this parameter for the four cases was calculated only numerically. Figure 11 shows the slag opening area for the four cases; Fig. 11(a) shows the highest opening area, which is reduced when the argon flow is divided into two inlets as shown in Figs. 11(b)-11(d). It is
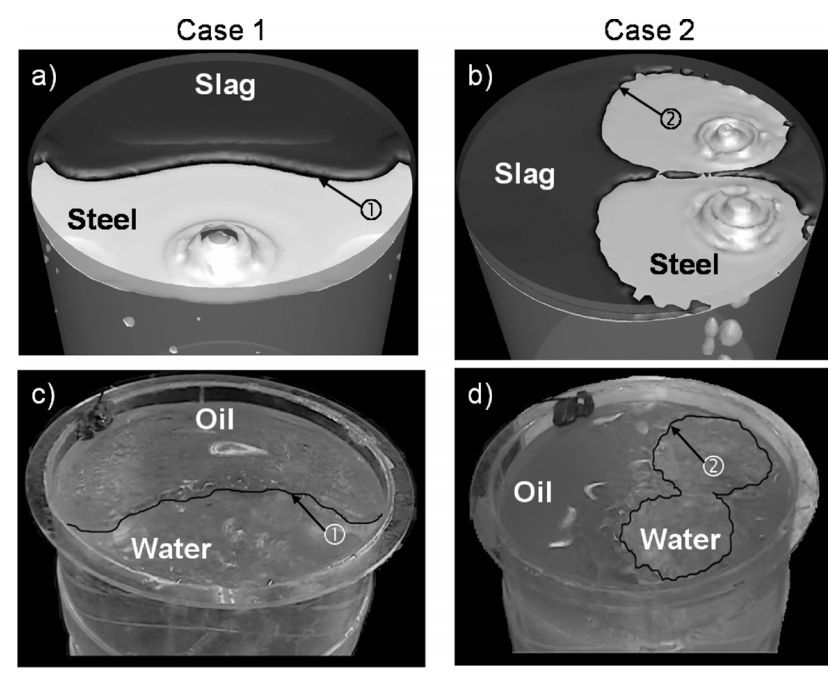

Fig. 10. Slag opening view for the cases 1 and 2, numerical simulation [a) and b)] and physical modeling [c) and d)].

a)
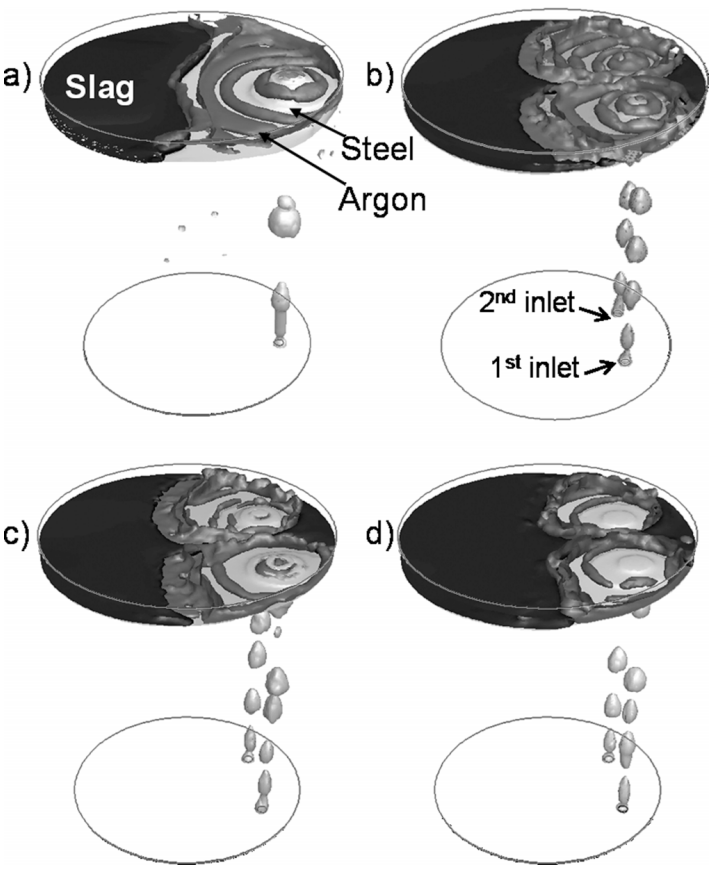

Fig. 11. Numerical slag opening results for all cases; a) case 1, b) case 2, c) case 3 and d) case 4 .

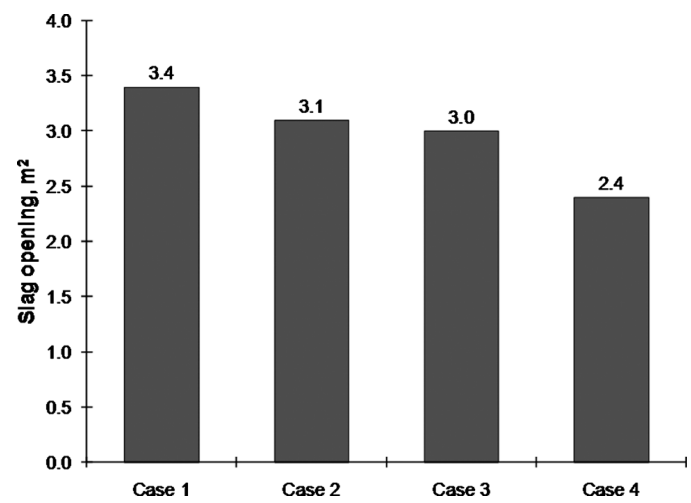

Fig. 12. Numerical quantification of the slag opening area for the four cases.

important to point out that Fig. 11(d) shows the smaller slag opening area; this is attributed to the inclination of the first argon inlet. Figure 12 shows the parameter quantification, 


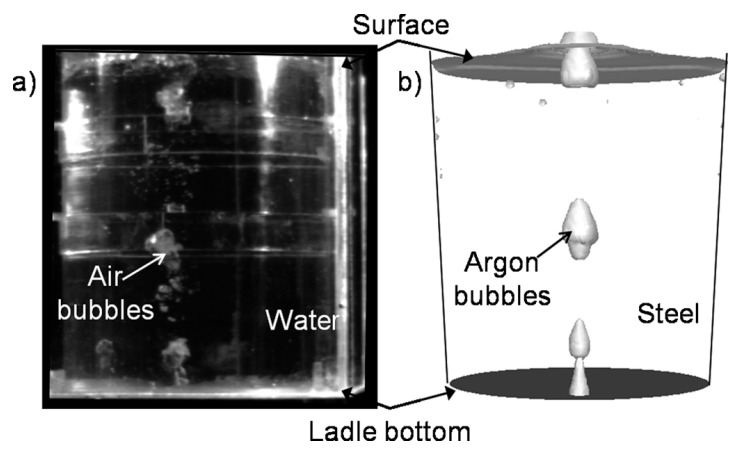

Fig. 13. Bubble plume structure; a) physical modeling and b) numerical simulation.

where is clear that the slag opening area is reduced from 3.4 to $2.4 \mathrm{~m}^{2}$ for the best case. Considering the above discussion, it can be established that case 4 gives the most optimum operation condition for the argon injection in the present ladle configuration, since this arrangement showed the lowest skin friction coefficient value and smaller slag opening area.

\subsection{Bubble Plume Formation}

Owing to the good agreement in the physical and mathematical modeling results in the parameters studied in the present work, it was worthwhile to study the bubbles plume formation, as illustrated in Fig. 13 for both models. Figure 13(a) shows a photograph taken in the water model using a high-speed camera at a given time for the case 1 arrangement. It was found that bubble plume is not formed by a continuous air phase, but from dispersed bubbles with different shapes and sizes, which ascend to the free surface leaving irregular distances among bubbles throughout its trajectory. Similarly, Fig. 13(b) shows an image taken from a numerical video of the argon injection at a given time; comparing both figures, it can be appreciated a very close matching of the plume structure. The numerical modeling shows to be a very powerful tool for the prediction of multiphase flow phenomena involved in ladle stirring operations. Finally, it is important to mention that despite the great similitude, this can be improved by considering no-drag forces (i.e. virtual mass, lift and turbulence dispersion) since these variables affects directly the bubble shape and its ascending trajectory.

\section{Conclusions}

A three-dimensional mathematical model to study argon gas injection into a typical steel ladle was developed, employing several inlets location arrays and the main conclusion can be drawn as follows:

(1) Despite that the mixing time is an important process parameter for ladle optimization, it is essential to consider other parameters, such as, slag opening area and ladle lining wear through wall skin friction coefficient.

(2) Case 4 gives the best operation condition for the argon injection in the studied configurations, since this arrangement reduced in a $63 \%$ the wall skin friction coefficient value and in approximately $1 \mathrm{~m}^{2}$ the slag opening area these respect to the case 1 .

(3) The results confirm that it is imperative to consider, for numerical simulation, the three phases present during ladle operations.

(4) A good agreement was obtained for the numerical and physical results, where the VOF model shows to be a powerful tool to simulate ladle gas stirring operation.

\section{Acknowledgements}

The authors give thanks to the institutions DGEST, ITM, UMSNH, CONACYT and SNI for their permanent support to the Academic Research Network on Mathematical Simulation of Materials Processing and Fluid Dynamics.

\section{Nomenclature}

$$
\begin{array}{ll}
v: & \text { Velocity }(\mathrm{m} / \mathrm{s}) \\
g: & \text { Gravity force }\left(\mathrm{m} / \mathrm{s}^{2}\right) \\
k: & \text { Turbulent kinetic energy }\left(\mathrm{m}^{2} / \mathrm{s}^{2}\right) \\
r: & \text { Bottom radius of vessel }(\mathrm{mm}) \\
S: & \text { Source term }
\end{array}
$$

Greek

$\mu, \mu_{t}: \quad$ Molecular and turbulent viscosity $(\mathrm{kg} / \mathrm{m}-\mathrm{s})$

$\rho: \quad$ Density $\left(\mathrm{kg} / \mathrm{m}^{3}\right)$

$\alpha$ : Volume fraction

$\varepsilon$ : Rate of turbulent kinetic energy dissipation $\left(\mathrm{m}^{2} / \mathrm{s}^{3}\right)$

\section{REFERENCES}

1) R. J. Fruehan: Ladle Metallurgy, ed. by Iron and Steel Society, Warrendale, PA, USA, (1985), 1.

2) G. G. Krishnamurthy, S. P. Mehrotra and A. Ghosh: Metall. Mater. Trans. B, 19B (1988), 839.

3) M. Iguchi, K. Nakamura and R. Tsujino: Metall. Mater. Trans. B, 29B (1998), 569.

4) Y. Takatzuka and M. Iguchi: ISIJ Int., 41 (2001), 124.

5) K. Aramaki: Patent No. 5945063, Aug. 31, (1999), US Patent.

6) M. Soder: Litentiate Thesis, Royal Institute of Technology, Sweden, (2001), 1.

7) K. Ogawa and T. Onoue: ISIJ Int., 29 (1989), 148.

8) P. T. L. Koh, N. C. Markatos and M. Cross: PCH Physic Chemical Hydrodynamics, 9 (1987), 197.

9) H. Turkoglu and B. Farouk: ISIJ Int., 31 (1991), 1371.

10) J. Szekely, T. Lehner and C.W. Chang: Ironmaking Steelmaking, 6 (1979), 285.

11) L. Zhang and S. Taniguchi: Mater. Process. Comp. Age, III (2000), 384.

12) Y. Y. Sheng and G. A. Irons: Metall. Mater. Trans. B, 26B (1995), 625.

13) P. Liovic, J. L. Liow and M. Rudman: ISIJ Int., 41 (2001), 225

14) T. Watanabe and M. Iguchi: ISIJ Int., 49 (2009), 182.

15) D. Mazumdar and R. I. L. Guthrie: ISIJ Int., 35 (1995), 1.

16) L. Jonsson and P. Jonsson: ISIJ Int., 36 (1996), 1127.

17) J. Mietz and F. Oeters: Steel Res., 59 (1988), 52.

18) K. Krishnapisharody and G. A. Irons: Metall. Mater. Trans. B, 37B (2006), 367.

19) N. Maruoka, F. Lazuardi, T. Maeyama, H. Nogami, G. S. Gupta, H. Shibata and S. Kitamura: Scanmet III, Conf. Proc., ed. by MEFOS, Metallurgical Research Institute AB, Lulea, Sweden, 2 (2008), 449.

20) H. Yang, U. Sand, J.-E. Eriksson and R. B. Fdhila: Scanmet III, Conf. Proc., ed. by MEFOS, Metallurgical Research Institute AB, Lulea, Sweden, 2 (2008), 459.

21) B. Li, H. Yin, C. Q. Zhou and F. Tsukihashi: ISIJ Int., 48 (2008), 1704.

22) G. Solorio-Diaz, A. Ramos-Banderas, J. de J. Barreto and R. D. Morales: Steel Res. Int., 78 (2007), 148.

23) T. Tamamori, M. Iguchi and M. Shitara: ISIJ Int., 45 (2005), 1211

24) T. Kagawa and M. Iguchi: ISIJ Int., 45 (2005), 1088.

25) W. P. Jones and B. E. Launder: Int. J. Heat Mass Transfer, 15 (1972), 301. 